\title{
Grade Inflation and Selection of students for medical education in Sri Lanka: The case for Merit and Equity
}

\author{
Indika Karunathilake
}

\section{Introduction}

Selecting students for medical education is a complex task. In Sri Lanka it is made even more complex due to the high demand and competitive nature of admission to medical schools. The selection process needs to be accountable to the society by selecting undergraduates with the potential to become good doctors who are competent to address health needs of the country; it also needs to be fair to applicants, who are diverse, unified only by their common desire to become doctors. Selection policies must also ensure equity, through provisions for educationally disadvantaged students as from underprivileged or rural areas. Similarly, expanding opportunities of access to private and fee-levying medical education leads to issues related to equity.

This article discusses the policies, method and process of selecting students for state Faculties of Medicine in relation to the principles of merit and equity within the current Sri Lankan context. ${ }^{1,2,3}$

\section{The National policy for Selection}

The national policy is to select medical students based on the performance at the General Certificate of Education - Advanced Level (GCE A/L) Bio Science Stream (consisting of Biology, Chemistry and Physics, along with a general knowledge test, Information Technology and English) examination. A student who has achieved a minimum of three simple passes for Biology, Chemistry and Physics is eligible to apply to the University Grants Commission (UGC) to study Medicine. Based on the z-scores for the mean scores for above three subjects, the students are selected as follows: of the total places to study medicine, $40 \%$ of available places will be allocated according to all island merit rank. Out of the remaining $60 \%, 55 \%$ of the opportunities are distributed to all the administrative districts of the country. Each district is given

Professor in Medical Education,

Faculty of Medicine, University of Colombo

karunathilake@hotmail.com; a quota according to the estimated midyear population of the district. This quota is filled by the students who achieve highest marks next to those who were included in the all island merit category in each district. The remaining $5 \%$ of the opportunities are distributed across 16 identified 'educationally disadvantaged' districts. ${ }^{4}$

\section{Procedure for selection}

The mean scores of GCE A/L Bio Science Stream eligible candidates are used to compute z-scores. Based on these z-scores, both the merit and district-based cut-off scores are determined, by the UGC. Once a candidate achieves the cut-off $s /$ he could indicate the medical faculties that $s /$ he prefers, in an order of preference. Depending on the demand for different Faculties of Medicine and the candidates' zscores, the UGC would allocate the candidates who have scored above the cut-off to different Faculties of Medicine. A candidate can attempt the above examination three times. The cut-off for all candidates, irrespective of the attempt at the examination, is the same for a given year. ${ }^{4,5}$

\section{Discussion}

\section{Methods used for selection}

Concerns have been expressed about the Medical School admission in Sri Lanka solely being based on the knowledge test. However, in almost all the leading medical schools worldwide, performance during the GCE $A / L$ or equivalent examinations is the main criteria for student selection. ${ }^{3,6}$

Large-scale research worldwide has proven that Advanced level performance is the best predictor of future academic performance, undergraduate, postgraduate and Continuous Professional Development. As shown by extensive research conducted in the UK and supported by many research studies worldwide, students' performance during high school education, undergraduate and postgraduate are mainly determined by their core-intellectual capacity, which es- 
sentially is like a "core-academic backbone". GCE A/L and similar examinations can measure this capacity reasonably accurately. ${ }^{7}$

Letters of recommendation and interviews as methods are now proven to be of questionable reliability and poor predictive validity. Cognitive or aptitude assessments and methods such as Multiple Mini Interviews (MMI), when they are used, are additional criteria and do not compensate for poor academic performance. Even in aptitude tests such as MCAT, the biology sub component has shown the best predictive validity. In the Sri Lankan context, the Advanced Levels (Biology stream) have been the yardstick for entry to medical schools. ${ }^{8,9}$

The challenge in introducing customized examinations for medicine such as aptitude tests, and other tests to assess non-cognitive abilities (e.g. MMI) is that these tests could disadvantage the students from rural and underprivileged areas, as coaching for these tests would give an advantage to the students representing a particular segment of the society. Another challenge in introducing tests for soft skills such as communication skills and teamwork is the logistical difficulties in conducting a countrywide test of this nature. ${ }^{10}$

It is noteworthy that there are positive developments within the current Sri Lankan A/L system such as inclusion of mandatory English, IT and project work. The knowledge of English language has also shown to be a determinant of success at the medical school, but imposing a selection criterion based on English knowledge would also further disadvantage the students from rural and socially disadvantaged backgrounds. ${ }^{11}$

\section{The Advanced Level results and admission by district quotas}

Affirmative actions with regards to medical school selection are not unique to Sri Lanka. Well-planned and precisely executed entry systems that favour the educationally disadvantaged are available in the developed world. For example, US medical school admission system has mechanisms to ensure racial and ethnic representation. ${ }^{12}$

District quota system is an affirmative action based on the principle of equity. Equity recognizes that for a variety of social, economic and historical reasons some are at a greater disadvantage than others, and strives to compensate them for their disadvantage. Equity recognizes this uneven playing field and aims to take extra measures by giving those who are in need more than others who are not.

There are confounding factors in this assumption; variations amongst schools in a district, mass tuition classes attended by students from other regions and migra- tion of high performing students to good schools in the cities to name a few. However, anomaly due to this subset is partially compensated by the national merit quota ( $40 \%$ of the total intake). Furthermore, even within the underprivileged districts, those who are getting low grades are a very small minority of outliers out of a total of over 1,300 students selected for Medicine. For example, according to UGC (2016) data ${ }^{13}$, in 2014, 30 students from Nuwaraeliya had 3Bs and above in 2014, and 32 students were selected for medicine, i.e. only two students who had grades less than $3 \mathrm{Bs}$ were selected for Medicine.

District quota system in Sri Lanka provides an opening for those students who are disadvantaged to enter higher education. However, affirmative action requires periodical revision considering the expansion of educational facilities and opportunities in the country. The district quota system was last revised in 1991. Like any other long-standing system, it is prone to be misused, thereby defeating the very purpose it is meant for. There is an urgent need for an evidence-based revision of the district quota system. ${ }^{11}$

\section{Minimum Criteria for eligibility}

The minimum criteria for eligibility $n$ students' selection should depend on the baseline performance applicable to the relevant population. The UGC stipulated eligibility criteria of three simple passes is now far outdated.

As far back as 1965, the minimum aggregate to enter a medical school in Sri Lanka was 145 out of a total of 400 (ie. average of 36.5 marks. The pass score was 40 marks even during that period. This was gradually increased with time. In 1983, it was 170 out of 400 . The Universities Act no 16 of 1978 stipulated four simple passes as the minimum eligibility criteria for university entrance based on these figures. ${ }^{6}$

Meanwhile, in early 2000, two major technical changes in the structure and pass or fail criteria of the A Level examination had occurred. In 2003, the number of subjects for the A Level examination was brought down from four to three. A new grading system was introduced in 2009 and the pass mark of the A Level subjects was brought down to 35 . In the biology stream alone, these two technical changes has led to an almost $100 \%$ increase of the number of students who pass the A Level examination within a time span of less than a decade (from 11,000 to over 20,000 ). This misleading numerical anomaly cannot be attributed to any meaningful improvement in the quality of education or the performance of students. These developments have made the minimum eligibility criteria of three simple passes redundant and outdated when it comes to selection of students for studying medicine in Sri Lanka. ${ }^{10}$

The current baseline performance of those who are se- 
lected to follow medicine is very high particularly due to grade inflation (ie. the grades obtained by students in successive years have become progressively higher). For example, in 2016, over 580 students obtained 3 "A"s in GCE A/L Biology stream. With such grade inflation, the rational and logical measure should be to make the bar higher. For example, UK is now considering $\mathrm{A}+$ or $\mathrm{A}++$ as minimum criteria. ${ }^{11}$ As shown below, the grades of those who had the minimum Z-scores for medicine selection too is on the rise.

\section{Table 1: Grades of the students selected with the lowest Z-scores}

\begin{tabular}{llll} 
Year & & \multicolumn{2}{c}{ Grades } \\
& & & \\
2010 & C & C & S \\
2011 & C & S & B \\
2012 & C & C & C \\
2013 & C & C & B \\
2014 & C & B & B \\
2015 & B & B & B
\end{tabular}

With current grade inflation, three simple passes as the entry criteria effectively makes candidates' ability to pay the sole criterion for medical education, leading to worsening of the disparities and a huge social injustice. 14 This becomes a serious concern within the Sri Lankan context considering the facts that, over $50 \%$ of the students (approximately 20,000 ) obtain $3 \mathrm{~S}$ or more during GCE A/L, increasing demand and competition for medical education, availability of access for private medical education limited to those who can afford under existing severe economic disparities.

\section{Conclusion}

Four distinct characteristics can be identified within the medical school admission system in Sri Lanka, i.e.,selection to all medical schools of the country being conducted at a national level, based on a national examination; selection based solely on a knowledge-based written examination; a strong policy on affirmative action to recruit students from disadvantaged backgrounds and a fairly low minimum eligibility standard to apply to medical school - though achieving this standard does not guarantee a place in a state medical school in Sri Lanka.

The medical school admission system in Sri Lanka is based on the principles of merit and equity. It has evolved with time and according to Sri Lankan context. As in any other system, there are several areas for improvement. But they can be achieved within the existing system maintaining the principles of merit and equity.

\section{References}

1. Hughes P. Can we improve on how we select medical students? Journal of the Royal Society of
Medicine. 2002; 95: 18-22.

2.McManus, IC "Student selection."In: A practical guide for medical teachers, edited by J. A. Dent and R. M. Harden. Edinburgh: Churchill Livingstone, 2001.

3.Bandaranayake RC Selection of students to medical school, The Ceylon Medical Journal. 50: 2005,4143.

4. University Grants Commission, Sri Lanka. Handbook for University admissions. 2018

5. Rajapakse, L. Selection of students for admission to a medical school in Sri Lanka. Ceylon Medical Journal. 2004;49: 147

6. De Silva KM. Affirmative Action Policies: The Sri Lankan Experience, Ethnic Studies Report. 1997; 15 (2): 129-133.

7. McManus IC, Dewberry C, Nicholson S, Dowell JS, Woolf K, Potts HWW. Construct-level predictive validity of educational attainment and intellectual aptitude tests in medical student selection: meta-regression of six UK longitudinal studies, BMC Medicine. 2013; 11:243

8. Donnon T, Paolucci EO, Violato C. The Predictive Validity of the MCAT for Medical School Performance and Medical Board Licensing Examinations: A MetaAnalysis of the Published Research, Academic Medicine. 2007; 82:100-106.

9. Mettananda, DSG, Wickramasinghe, VP, KudolugodaArachchi, J, Lamabadusuriya, SP, Ajanthan, $R$, Kottahachchi,WD, Suitability of selection criteria as a measure of outcome of medical graduates: University of Colombo, The Ceylon Journal of Medical Science, 2006;49: 1-12

10. Karunathilake I M. Merit and Equity are the Key Principals of Selecting Students for Medical Education, Sunday Morning, 21st October 2018

11. Mendis L, Karunathilake I \& Ponnamperuma G. Admission of Sri Lankan students for medical education: time to review, Ceylon Medical Journal. 2018;63 (2): 49-52.

12.De Silva NR, Pathmeswaran A, de Silva HJ Selection of students for admission to a medical school in Sri Lanka,The Ceylon Medical Journal, 2004; 49: 81-85.

13.University Grants Commission (UGC) Sri Lanka Sri Lanka University Statistics. 2016

14. Karunathilake I M. Seven Myths Regarding Selection of Students for Medical Schools, Sunday Morning, 7th October 2018 